\title{
Inspired by competition
}

\author{
Science competitions in secondary school can inspire students and teachers alike, as Eric Plum, now a \\ lecturer, and his former teacher Walter Stein explain.
}

$\mathrm{M}$ ost winter evenings and weekends, the science labs of St. MichaelGymnasium secondary school in Bad Münstereifel, Germany, are bustling with students. They are busy designing experiments, setting up instrumentation, and finalizing reports for the annual Jugend forscht youth science competition. Awards include cash prizes, research internships, and an opportunity to meet the Chancellor.

For many pupils this is the only chance to work on a project at the cutting edge of scientific knowledge. For others, this is the beginning of a career in science. Initially motivated by potential awards and national recognition, students soon start to experience the range of emotions that researchers grapple with in labs around the world, as they immerse themselves in their project: the struggle to get the project going, the frustration of having to modify the initial plan, the realization that perseverance and resourcefulness are essential to make things work, that addictive sense of achievement when another small problem is solved, and looking back on their accomplishments with pride. Along the way, students learn how to gather relevant information, approach experts in academia and industry, and present their work to others.

It is important to motivate students from the start by choosing the right research project. Ideas might come from important societal challenges, such as global warming and sustainability, or recent scientific breakthroughs dominating the news, such as the advent of graphene or metamaterials. Teachers should make sure that the students embark on realistic projects and consider the time and instrumentation required. In the end, a winning project may well be one that translates a hot research topic into a simple classroom demonstration.

For example, students at St. MichaelGymnasium became national champions for making carbon nanotubes. Initially, nanotubes were synthesized using a homemade arc chamber and characterized by electron microscopy at RWTH Aachen University. At school, detection of carbon nanotubes presented a major challenge. However, a literature search and

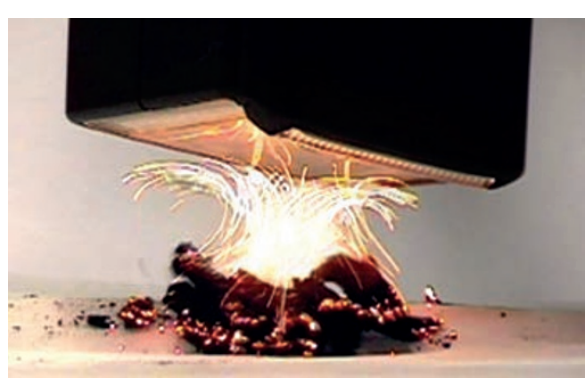

simplification of the experiment eventually led to the production of nanotubes in a metal bucket, which were detected using a camera flash (see image). In another outstanding project, students made graphene sensors. Graphene was synthesized by the 'Scotch tape method', a more manageable endeavour for a secondary school lab, but making precise electrical connections to a small graphene flake was the challenging part. A bulky contacting apparatus consisting of three optical microscopes was built, before the students succeeded in making reliable microscale contacts using homemade indium tips. The final devices included a field-effect transistor and a gas sensor that could detect ammonia, hydrogen and ozone. The full database of projects can be found at www.jufo.stmg.de/en/. Other notable examples include making microwave metamaterials, photonic crystals and nanowires.

Such research projects greatly benefit all concerned parties: students, teachers and researchers willing to get involved in outreach activities. Many students keep fond memories of the time spent in the $\mathrm{lab}$ and relish the intellectual growth they experienced. For some this experience is the springboard for a career in science. For example, after graduating, I, Eric Plum, had the chance to spend two months at the Max Planck Institute for Radio Astronomy, where I analysed radio measurements and developed a simple model of pulsars neutron stars emitting radio pulses - for which I won the national award of the German Aerospace Centre. In turn, these early achievements were instrumental for the success of my application as a Fulbright visiting scholar at New Mexico Tech, USA, and, later, my $\mathrm{PhD}$ application to the University of Southampton, UK.

The school can get valuable publicity from nationwide exposure, build on its reputation and attract stronger applicants. Since 1986, students of St. MichaelGymnasium have conducted 183 awardwinning science projects, and as a result students and teachers have had the honour of meeting the last two Chancellors, four German Presidents and a Nobel laureate. Teachers who engage in the scientific endeavour with their pupils can escape the monotony of daily classroom life and enter a stimulating uncharted territory that keeps them abreast of the latest scientific developments and reignites their love for science. The teacher's main task here is to find ways to break down a big research challenge into smaller tasks that can be handled by the students to avoid discouragement. Finally, for established researchers from research institutions who may be keen on advising eager young students, these projects provide an enjoyable way to fulfil the funding agencies' mandate for public outreach of science.

High-quality research projects in secondary schools can only exist on a voluntary basis. Students and teachers will only spend their evenings and weekends at school because they want to overcome the challenges they have set for themselves. All that schools and governments need to do is to facilitate an environment where such activities are encouraged and valued. While initiatives aimed at helping struggling students on their educational path are certainly noteworthy, it is also essential to offer opportunities to the most talented to excel so as to nurture the next generation of leaders for the benefit of all.
ERIC PLUM is a Leverhulme research lecturer at the Optoelectronics Research Centre and Centre for Photonic Metamaterials, University of Southampton, Highfield, Southampton SO17 1BJ, UK. WALTER STEIN is a physics teacher at St. Michael-Gymnasium, Markt 11, 53902 Bad Münstereifel, Germany. e-mail:erp@orc.soton.ac.uk; Walter_Stein@t-online.de 